\title{
HISTORIA DEL PAISAJE RURAL ENTRE LAS FAMILIAS DE PAPOSO Y TALTAL
}

\author{
HISTORY OF THE RURAL LANDSCAPE AMONG \\ THE FAMILIES OF PAPOSO AND TALTAL
}

\author{
José Castelleti*, Maximino Villarroel ${ }^{* *}$, \\ Humberto Almendares ${ }^{* * *}$ y Pedro Mercado ${ }^{* * * *}$
}

\begin{abstract}
Recientes investigaciones etnográficas permiten corroborar entre los grupos "chango" o "camanchaca" de la comuna de Taltal en la costa arreica andina, el desarrollo de un mapa territorial compartido fundamentado en la familia extendida como núcleo básico (Gutiérrez y Lazo, 1996; Lazo y Téllez, 1984; Castelleti, 2017; Gárate, 2011). Dichas familias presentan un modo disperso de ocupación territorial, como resultado de su histórica alta movilidad luego de siglos de imposición del sistema de encomiendas y las economías nacionales (Castro et al., 2012; Escobar y García, 2017; Larraín, 1978; Philippi, 1860). Contrariamente a este hecho, las familias locales históricamente han ocupado el territorio rural desde el espacio habitacional/productivo de las majadas, cuyo poblamiento ha supuesto un férreo sistema de alianzas. Se presenta aquí el rastreo de las redes familiares locales, a partir del registro familiar Almendares, grupo cuya documentación lo muestra habitando la costa arreica a lo menos desde 1622 (Casassas, 1974).

Palabras claves: Mapa territorial, familias Chango o Camanchaca, costa arreica andina, los Almendares, continuidad cultural.
\end{abstract}

Recent ethnographic research allows corroborating between Chango or Camanchaca groups of the Taltal district on the west coast of South America, the development of a shared territorial map based on the extended family as a basic nucleus (Gutierrez and Lazo, 1996, Lazo and Tellez, 1984, Castelleti, 2017; Garate, 2011). These families show a dispersed mode of territorial occupation as result of their historical high mobility, achieved by centuries of imposition of the Encomienda system and national economies (Castro et al., 2012, Escobar and Garcia, 2017, Larrain, 1978 Philippi, 1860). In contrast, local families have historically occupied the rural territory from the housing/productive space of the majadas, whose settlement has led to a strong system of alliances. The tracing of local family networks is presented here from the Almendares family registry, a group whose documentation shows it inhabiting the coast of Arica at least since 1622 (Casassas, 1974).

Key words: Territorial map, Chango or Camanchaca family, Andean arreic coast, Almendares family, cultural continuity.

\section{Introducción}

Nuevos registros etnográficos acerca de los habitantes costeros entre Paposo y Taltal, además de una reevaluación de las fuentes de información disponibles para los siglos XVII en adelante (Castelleti, 2017), permiten ampliar la discusión respecto del proceso de ocupación territorial llevado a cabo por las familias paposinas, en el contexto histórico desde la instalación de la Estancia de Paposo en 1679 hasta hoy (Aldunate et al., 2010; Castro et al., 2012; Escobar y García, 2017).

Durante la última década hemos sido testigos de un importante auge en la investigación de los grupos culturales changos de la costa meridional andina, rebasando actualmente dicha problemática el campo exclusivamente académico, debido a su inminente decreto como "pueblo originario" en la legalidad chilena (Comisión Verdad y Nuevo Trato, 2008). Al igual que con el tema Chango, asistimos en la actualidad a una apertura hacia la investigación sistemática de contextos locales, entendiéndoles como el espacio en el que más claramente se evidencia el conflicto "objetivación/subjetivación" en la práctica social y la conformación del paisaje (Geertz, 1983; Bourdieu, 1980). El paisaje, por tanto, ha pasado a comprenderse como un constructo dinámico creado por la acción social con el tiempo, en que se condicionan mutuamente la materialización física e ideacional de una manera de cohabitar entre actores humanos como también no humanos, junto con la generación de sujetos físicos y sociales; red

\footnotetext{
* Universidad de Tarapacá, Departamento de Antropología, Arica, Chile. Correo electrónico: jcastelleti@ uta.cl

** Habitante de Taltal. Chile. Correo electrónico: maxnicolasvil@gmail.com

*** Habitante de la majada de Bandurria. Chile ( $\dagger)$.

*****Habitante de Taltal. Chile. Correo electrónico: pejame@ gmail.com
} 
en la que interactúan o conviven en conflicto los diversos grupos habitantes, materializando cada grupo humano sus propias interpretaciones acerca del pasado o acerca del rol agencial que en sus vidas puedan tener actores tanto humanos como no humanos, tales como objetos, lugares o animales (Criado, 1999; Latour, 2005; Ricoeur, 2003; David y Thomas, 2008).

Muchos estudios etnográficos en Chile han optado por la transdisciplinareidad y la integración de categorías topográficas o vegetacionales de uso local para el registro del paisaje (Aldunate et al. 2003, 2010; Castro et al. 2004; Villagrán, et al., 2003; Villagrán y Castro, 2012), rescatando la oralidad y narrativas tradicionales (Kalazich, 2015) deconstruyendo la identidad de género en el discurso de mujeres aymara (Gavilán y Carrasco, 2018) o contrastando la documentación con mitos locales (Escobar y García, 2017), constituyéndose así dichas investigaciones y sus autores en actores importantes en la visibilización de la memoria de los grupos culturales en estudio (Gundermann, 2000; Ayala, 2007; Aravena, 2014; Rock, 2016; Romero, 2003). Para la zona de los canales de Chiloé, por ejemplo, un importante trabajo desarrollado por F. Ther Ríos (2011) ha apuntado a considerar el "maritorio" o territorio marino como el soporte físico de un paisaje depositario de la memoria e imaginario de los grupos humanos costeros, que se crea constantemente permitiendo la reproducción y proyección de simbolismos, economías y visiones del tiempo costero.

La información oficial para la zona de Paposo y Taltal permite establecer que a la par con el proceso de nucleamiento de la población local en torno a Paposo desde 1679 (Hanisch, 1984; Sayago, 1997), los grupos familiares locales mantendrán sus enclaves poblacionales tradicionales junto con las fuentes de agua o "aguadas", además de su dispersión en "caletas" o núcleos ocasionales de población costera (Capdeville 2009, Gimeno, 2008; Gutiérrez y Lazo, 1996). Con este escenario, dichos enclaves serán testigos del proceso de transformación de las familias locales al modo de vida pescador-arriero-minero histórico, el que se consolidará con la industria minera desde fines del siglo XIX (Capdeville, 2009; Castelleti, 2017; Castro et al., 2012; Hanisch, 1984; Lazo y Téllez, 1984; Philippi, 1860; Sagredo y González, 2004; Sayago, 1997).

Sin embargo, a pesar del cúmulo de información registrada en torno a los grupos Chango, diversos aspectos no del todo investigados dejan entrever un conflicto latente en la conformación del paisaje local, donde la invisibilización del grupo cultural Chango es solo un indicador (Comisión Verdad y Nuevo Trato, 2008). El trabajo que a continuación se entrega es el resultado de un diálogo surgido entre los autores, todos habitantes de la costa arreica andina, el que ha buscado generar una mirada crítica respecto del registro oficial documentado para la historia del paisaje rural entre Paposo y Taltal (Figura 1), a partir del rastreo del registro escrito $\mathrm{y}$ oral en torno al grupo familiar local Almendares, el que ha implicado la revisión y cotejo de fuentes escritas, como también el registro del encuentro con algunos de sus miembros (Castelleti, 2017). La presente investigación busca dar luces a las preguntas fundamentales acerca del rol que tomó y ha tomado el conflicto en torno a "lo chango" en la conformación histórica del paisaje local de Paposo/ Taltal, otorgando nuevas fuentes de información para la discusión del patrimonio material y humano de la etnia o grupo cultural chango o camanchaca en la costa arreica del desierto de Atacama, y con esto contrarrestar en parte la invisibilización a que esta agrupación ha sido sometida (Castro et al., 2012; Escobar y García, 2017).

\section{Mapa de relaciones de parentesco camanchaco/chango entre los siglos XIX y XXI y sus antecedentes históricos}

\subsection{Las familias tradicionales camanchaco/ chango en los documentos eclesiásticos y civiles}

Sabemos que las actuales denominaciones para las familias indígenas costeras entre Paposo y Taltal habrían sido adquiridas con la obligatoriedad del traspaso de apellidos en territorio español impulsada desde el siglo XVI y sistemáticamente desde el siglo XVII por la Corona española y el alto clero católico ${ }^{1}$ (Bittmann, 1977; Casassas, 1974), apellidándose dichos grupos costeros desde entonces como Almendares, Gutiérrez, Morales, Castillo, Mondaca. Chirino, Salas y Caruncho, principalmente (Gimeno, 2008; Gutiérrez y Lazo, 1996; Hanisch, 1984; Lazo y Téllez, 1984; Sayago, 1997). Es probable que la variedad de grupos familiares en la costa arreica meridional obedezca originariamente a la plurietnicidad costera descrita desde momentos precontacto (Aldunate et al., 2010; Larraín, 1978), notablemente influenciada luego de fundada la Estancia de Paposo en 1679, por nuevos procesos de alianza y mestizaje con grupos aimaras, 


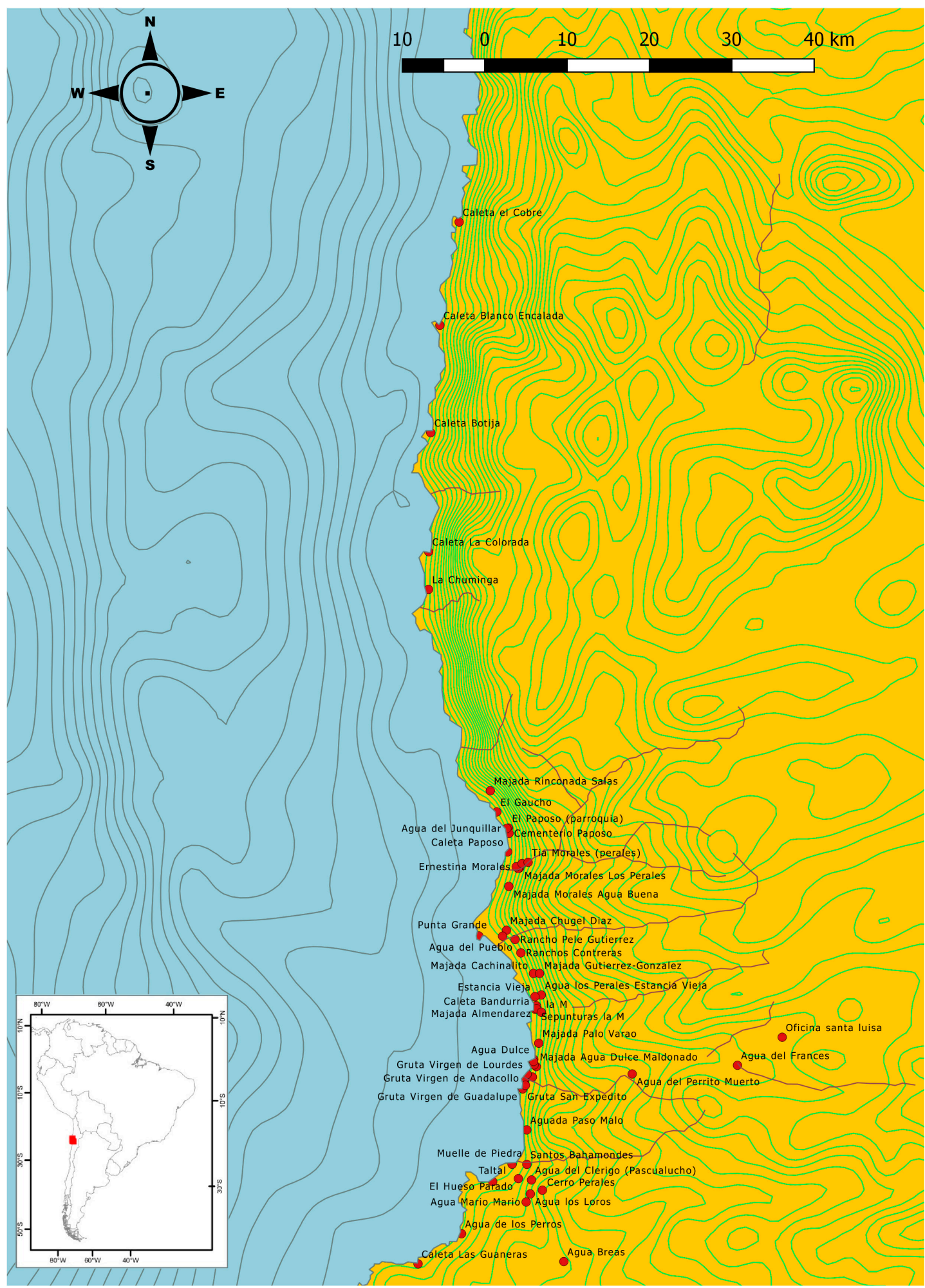

Figura 1. Mapa de la zona Taltal y Paposo, con los principales hitos histórico/subactuales relatados en este artículo. Autora: Francisca Campano Núñez. 
atacameños y diaguitas, y recurrentemente también con advenedizos históricos, resultando finalmente las familias camanchaco/chango actuales (Henríquez et al., 2004; Rothhammer et al., 2010).

Las primeras referencias a apellidos de origen español usados por familias indígena-mestizas de la costa arreica aparecen en el "Libro de Varias Ojas" de la parroquia de Chiuchiu (LVO), el que consigna el registro eclesiástico de 1611 a 1750 para la caleta de Cobija, $280 \mathrm{~km}$ al norte de Paposo, apareciendo aquí el apellido Almendares (Almendariz) junto con otros como Maturana, González, Otal, Ligero, Yaychas (Ayta, Aytas), Cotaypy, Saxaya (Sajaia, Sacaia), Chuquina, Chayilli, Chivillapo y Chacón (Casassas, 1974; Bittmann, 1977), coexistiendo con individuos catalogados de "camanchaca" apellidados Collama, Colamar, Chucho, Cauallolo, Caun, Liquena, Ycotan y Unca (Castro, 2009), junto a apellidados catalogados de "pro-anche" desde 1656, como son Alaguana (Jaguaña), Chacaguaina, Anchuño, Clapiche (Chalpiche), Cancota, Coimas, Cherepe, Chamalco, Chiquin, Lacmor, Laicor, Maqueta, Quilama y Sacaya (Sajaya, Sacalla) (Bittmann, 1977; Castro, 2009).

Luego de la fundación de la Estancia de Paposo en 1679 (Hanisch, 1984), serán varios los viajeros que den cuenta aquí del proceso de nucleamiento poblacional entre las familias costeras locales (Bollaert, 1860; Gay, 2010; Mellet, 1824; Philippi, 1860, entre otros). Sin embargo, serán escasos los registros escritos de sus apellidos (Lazo y Téllez, 1984; Matte Varas, 1981), destacando solo los de Almendares y Zuleta (Autos de ACALS, 1758: Hanisch, 1984). Así, y con motivo de la visita de Ambrosio O'Higgins a Caldera en 1789, se registra por ejemplo la destitución del diputado territorial de la Estancia de Paposo, José Zuleta, según consta en oficio del 16 de julio de 1789, aceptando el nombramiento de Gregorio Almendares en ese puesto el 11 de noviembre del mismo año (Lazo y Téllez, 1984; Sayago, 1997). Gregorio Almendares, hijo de José Almendares y Catalina Maturano, ya ocupaba desde 1773 el cargo de "Oficial de Caballería de la Costa", el que desde 1789 lo ejercerían Francisco, Félix y Eulalio Zuleta (Suleta) (Gutiérrez y Lazo, 1996; Lazo y Téllez, 1984; Sayago, 1997). Para qué decir del censo e informe que en 1793 O'Higgins ordena confeccionar al diputado territorial Gregorio Almendares (Almendáriz) ${ }^{2}$ (Sayago, 1997), siendo finalmente Félix Zuleta su redactor, ya que Almendares no sabía escribir (Hanisch, 1984).

El primer registro escrito de los apellidos de los grupos chango de Paposo será llevado a cabo por los franciscanos Tomás Araya e Isidoro de la Barrera durante su misión presumiblemente entre 1803 y 1807 (Lazo y Téllez, 1984), informe que con posterioridad será recogido y complementado por el presbítero Rafael Valdivieso en su misión de 1841 también en Paposo (Matte Varas, 1981). La matrícula de Araya y Barrera da 233 habitantes, detallando un alto número de individuos apellidados Almendares y Suleta $(42,4 \%)$, correspondiendo el resto a los apellidos de origen español Maldonado, Torres, Valdivieso, Castillo, González, Sandoval, Carrasan, Velásquez, Maturano, Dias, Barastain, Arazena, Figueroa, Copa, Contreras, Baca y Arenas, además de los de origen indígena Cotaipy (siete casos), Sajaya (cinco casos), Caruncho (16 casos) y Chiquillapo (cinco casos) (Lazo y Téllez, 1984).

Es probable de esta manera que durante los siglos XVII al XIX la Estancia de Paposo con sus dependencias administrativas y el atracadero seis $\mathrm{km}$ al sur (Philippi, 1860), se configurase como un núcleo poblacional permanente, donde predominaban los apellidados Suleta (Zuleta) y Almendares, población que articulaba una amplia red de caletas y rancheríos costeros que dispersaron dichos apellidos, como describe Bollaert en su viaje de 1828:

At Punta Grande were three or four families of Changos, and at Agua Dulce half a dozen more, who had a few goats and asses. Having traversed the dangerous Mal Paso, I came to Hueso Parado, 2530' (this spot was shown to me as the divisional point with Bolivia). At Salinas I found four or five families of Changos; and as they had just then been supplied with wine by the purchasers of their dried fish, wild dancing and singing continued all night (Bollaert 1860:171). ${ }^{3}$

A partir del Tratado de Tregua de 1884 firmado entre Chile y Bolivia finalizando la Guerra del Pacífico, se comenzará a implementar sistemáticamente el registro eclesial y civil en la costa andina (González Pizarro, 2002). La revisión del Archivo Central de Documentación Eclesiástica del Arzobispado de Antofagasta (ACDEAA) (Castelleti, 2017) ha permitido acceder a los libros de inscripción de bautismos de la parroquia de Taltal desde su implementación en 1879. De esta manera, se tiene registro que los apellidos más comunes entre las familias indígena/mestizas costeras desde 1879 
serán Caruncho y Almendares, junto con Maldonado, Aracena, Gutiérrez, Morales, Díaz, Zuleta, Contreras, Salas, González y Álvarez, al igual que otros de adscripción indígena foránea como Camplanchai, Jaguar y Lajaña, sumando 41 bautizados con adscripción indígena/mestiza (muchos registrados como hijos naturales, conducta costera habitual), de 164 bautizados dicho año (Libro I de bautizos parroquia de Taltal, ACDEAA).

Los registros del Arzobispado de Antofagasta permitieron igualmente registrar el proceso de alianzas entre las familias costeras locales durante el auge de la industria del salitre (ca. 1877-1930), lo que supuso la llegada de contingentes foráneos al cantón Taltal (Castro et al., 2012; Escobar y García, 2017; Gutiérrez y Lazo, 1996). No obstante -creemos- esta afluencia poblacional hacia la costa es el resultado de circuitos regionales de larga data y que evidencia a grupos que desde antaño recorren la redes de movilidad e intercambio regional desde y hacia la costa (Aldunate et al. 2010). A modo de ejemplo, durante fines del siglo XIX e inicios del XX el desarrollo de la minería del salitre permitió la expansión del departamento de Taltal hacia un sinfín de "oficinas salitreras", lo que supuso un aumento poblacional (Gimeno, 2008; Gutiérrez y Lazo, 1996). Para 1907 por ejemplo se registran 897 bautizos en la parroquia San Francisco Javier de Taltal, de los que 341 correspondieron a óleos celebrados en oficinas salitreras del cantón. Del total de bautizados del cantón, 103 personas evidenciaron su primer apellido de filiación indígena-mestiza (35 como hijos naturales) y 59 su segundo apellido, siendo los más frecuentes González, Álvarez, Contreras, Maldonado, Díaz, Morales y Castillo, registrándose en menor frecuencia Gutiérrez, Salas, Chirino, Chazarro, Mondaca y Mercado, Araya y Valdés, coexistiendo con apellidos indígenas foráneos aimara, diaguita y mapuche como Campillay, Payante, Caimanque, Abayay, Collante, Tamblay, Llaume, Chacana, Magüida, Liquitai y Alcayaga (Libro VII de Bautismos parroquia San Francisco Javier de Taltal, ACDEAA).

\subsection{Los Almendares y su percepción del paisaje social de Paposo/Taltal}

\subsubsection{Los Almendares}

Durante las temporadas de campo entre febrero y julio de 2014 y febrero-marzo de 2015, se entablaron gratas conversaciones con don Humberto Almendares, de 80 años, uno de los miembros de mayor edad de la familia Almendares, descendiente de los antiguos grupos costeros indígenas ${ }^{4}$. Nacido en la caleta Bandurria en 1935, específicamente a los pies del camino conocido como "la M" (figuras $1,2)$, su padre fue el encargado de la crianza de burros para el transporte entre las minas del interior y el puerto de Bandurria (Figura 3).

Don Humberto es descendiente directo de Manuel Caruncho González, amigo e informante de Augusto Capdeville a principios del siglo XX (Capdeville, 2009). Nos dijo que su abuelo el "Chango" González, por motivos que él desconoce, al inscribir a su madre y hermanos en el registro civil lo hizo apellidándoles González y no Caruncho ${ }^{5}$, perdiéndose así esta rama del apellido. El padre de Manuel Caruncho González no sería originario de la costa de Taltal sino de Bolivia o Argentina, llegado a la zona de Bandurria por la ruta costa/ interior, hecho concordante con la información entregada por apellidados Almendares de otras ramas familiares, como es el caso del artesano en madera de copao Mario Caruncho Almendares (ca. 70 años), el conocido "Mario Mario" de Taltal, quien asegura descender de apellidados Caruncho venidos de Argentina.

El discurso de don Humberto es ambiguo en relación con la probable ligazón étnica de su familia con los pobladores de los sitios arqueológicos del sector de Bandurria y Estancia Vieja donde su familia habitualmente ha morado (Figura 1). En una ocasión al preguntarle acerca del origen de las terrazas de cultivo abandonadas en la aguada de "Los Perales" en los altos del Morado, me dijo que a sus padres le habían contado que dicho lugar habría sustentado una gran población, pero dada su antigüedad, ya en ese entonces se desconocían detalles de tal poblamiento. Ante mi pregunta si consideraba que podrían haber estado apellidadas Almendares dichas poblaciones, me contestó: "probablemente" (Castelleti, 2017).

El rancho de don Humberto (Figura 2) está construido a los pies de un pequeño promontorio rocoso y lo conforman seis estructuras de techos de cinc de un agua y paredes de madera, metal y plástico, dos de estas son habitaciones de pernocte y comedor, unidas a una tercera que es lavatorio y cocina, separadas del gallinero, los corrales para cabras y la ducha, por un espacio abierto. Tanto enfrente como atrás de la casa principal don 


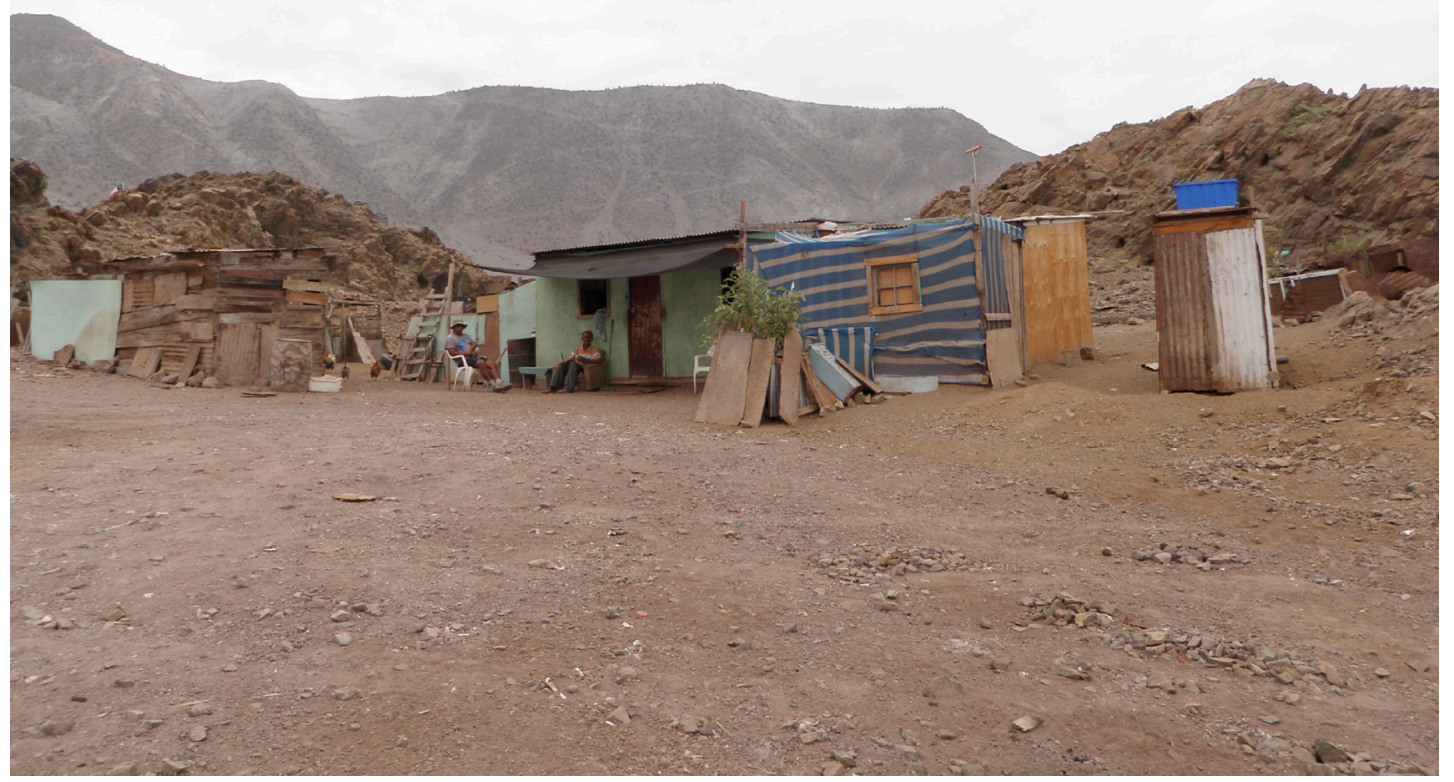

Figura 2. Rancho de don Humberto Almendares (en la imagen junto a Pedro Mercado). Autor: José Castelleti D.

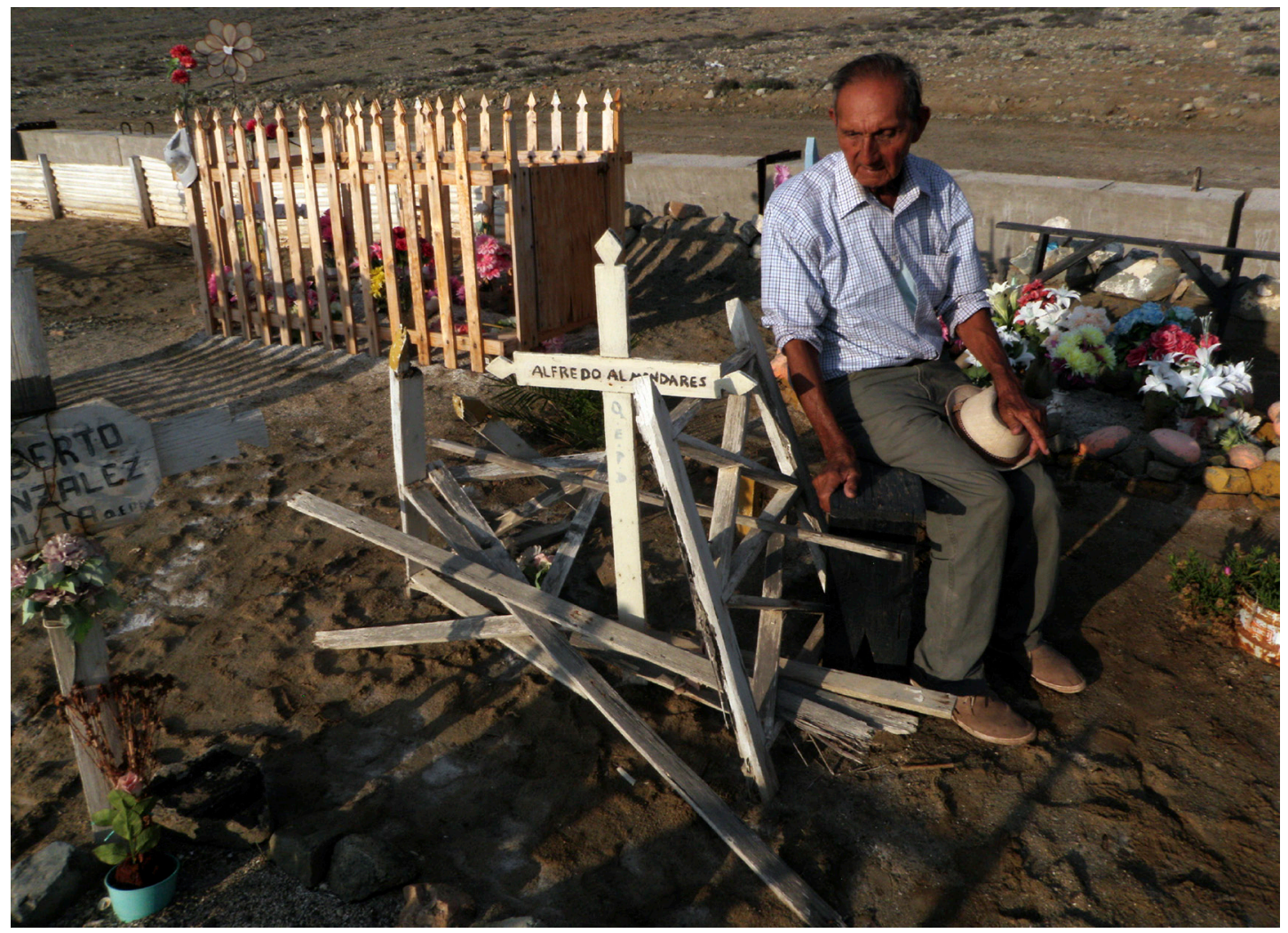

Figura 3. Don Humberto Almendares en la tumba de su padre. Autor: José Castelleti D. 
Humberto tiene plantados algunos arbustos como matico, ruda, cardenal y malva rosa.

En la actualidad la majada de Bandurria la conforman el rancho de don Humberto junto con un par de ranchos de sobrinos, además de las instalaciones del "Sindicato de Huireros de Taltal", dirigido por un tronco de la familia Morales, y por la casa de la amiga de don Humberto, doña Marlén Morales.

\subsubsection{Cachinalito}

El sector de Cachinales, en torno a la zona de la desembocadura de la quebrada homónima, es el territorio que tradicionalmente ha ocupado la familia Gutiérrez, una de las más conocidas y antiguas de la zona (Gimeno, 2008; Gutiérrez y Lazo, 1996). En Cachinales, dicha familia ha entrado tradicionalmente en alianza con los Castillo, otro grupo familiar de origen indígena/mestizo local, así como también en menor medida con los Morales y los González (Caruncho) (Gimeno, 2008; Gutiérrez y Lazo, 1996). La majada de los Gutiérrez (o CastilloGutiérrez como se les conoce), se emplaza a los pies de la quebrada de Cachinales, vecina al tradicional afloramiento "Aguada de Cachinalito" (Figura 1), a partir del cual los diversos hijos del grupo familiar han ido construyendo sus casas y ranchos extendiendo el área de la majada, reconocida por sus antiguos perales, higueras y plantas medicinales. Los Gutiérrez, señala Humberto Almendares, han establecido alianzas matrimoniales con muchas de las restantes familias costeras, construyendo nuevos núcleos habitacionales en el perímetro de Cachinales, como la majada de "Las Losas" de Roberto Gutiérrez, levantada por su padre Bernardo Gutiérrez (hermano de don Segundo Gutiérrez) hacia la década de 1970 (Castelleti, 2017).

La cabeza visible de la familia Gutiérrez durante el siglo XX e inicios del XXI fue don Segundo Gutiérrez Álvarez, nacido en 1905 en Estancia Vieja e hijo del colla ${ }^{6}$ llegado a la zona Bernardo Gutiérrez Cóndor, y de la habitante costera Tránsito Munizaga (Gimeno, 2008). Don Segundo se crió en la Aguada de Cachinalito donde al pasar de los años fue cabrero, minero y mariscador, recorriendo toda la sierra Esmeralda y las salitreras como vendedor ambulante a lomo de mula, ofreciendo charqui y quesos de cabra junto con pescados y mariscos secos. Don Segundo se casó con Filomena Morales Díaz, también descendiente de las familias costeras, criando una numerosa familia que siguió confeccionando los quesos de cabra y vendiendo las peras "de pascua" típicas de las majadas. Ferviente seguidor de la "Virgen de Andacollo", don Segundo muere en 2003 a la edad de 98 años (Gimeno, 2008).

Entre los Gutiérrez, al igual que entre otras familias costeras, es habitual que desde los núcleos residenciales se articulen "caletas" o pequeñas poblaciones vecinas a la línea de costa, con el fin de acceder y controlar los recursos de playas distantes hasta $50 \mathrm{~km}$ o más. Es el caso del conocido núcleo poblacional "La Chuminga", pequeña caleta construida por un miembro de los Gutiérrez hace 40 años y llamada así por la vecina mina "La Chuminga", constituyéndose hasta hoy este enclave en un punto tradicional en la ruta de recolección del huiro entre Paposo y Caleta El Cobre (Castelleti, 2017).

\subsubsection{Las alianzas familiares de los Almendares y Gutiérrez con otras familias de Paposo y las majadas}

Alrededor de 14 son las familias indígeno/ mestizas que conforman el ambiente social de Paposo y sus alrededores, todas ellas con registro histórico (Matte Varas, 1981; Sayago, 1997). Don Humberto Almendares percibe y retrata muy claramente la red de alianzas familiares de Paposo, pues sus principales aliados, los Morales y sobre todo los Contreras, lo ayudan a configurar una memoria familiar y un mapa territorial específico (Figura 1). Los Contreras, cuya majada se emplaza en el piedemonte de la ladera sur de la desembocadura de la quebrada de Matancillas, conforman un grupo familiar indígena-mestizo cuyo apellido aparece en los registros escritos desde hace dos siglos (Lazo y Téllez, 1984; Matte Varas, 1981; Thayer Ojeda, 1989). Los Contreras, al igual que las restantes familias chango, se han integrado a la ciudad de Taltal manteniendo también su pequeño núcleo habitacional en las majadas, donde cultivan pequeñas hortalizas y olivos a partir de la obtención de agua desde la quebrada de Potrerillos. Detalla don Humberto que le une una amistad especial con los Contreras, sobre todo luego de haber vivido con ellos por casi cuatro años y compartir la religión pentecostal.

Inmediatamente al sur de Punta Grande se encuentra la denominada "Agua del pueblo". En un viaje al área, don Humberto me platicó que en torno al "Agua del pueblo" se habría emplazado un 
poblado antiguo, del que hoy solo quedan escasas estructuras en ruinas. La rinconada del Agua del pueblo se encuentra actualmente ocupada por la familia de "Chugel Díaz", descendiente de la familia tradicional Díaz. Sin embargo, antaño este lugar habría estado ocupado -según don Humberto- por la familia tradicional Morales, quienes aquí habrían sido cabreros y crianceros de caballos para luego instalarse más al norte en la Rinconada de Agua buena.

Desde Bandurria al sur la geografía define altas terrazas erosionadas por la desembocadura de quebradas. En una ocasión don Humberto me platicó acerca de la antigua ocupación del área por algunas familias tradicionales, de la que solo se observan ruinas. En la desembocadura de la quebrada de Agua Dulce, unos km al interior de la playa denominada "El 20", dos familias habrían levantado las majadas del sector: la familia local de los Chirino y la familia de los Caballero, originaria esta última del sur de Chile. Los Chirino, hoy muchos de ellos dedicados a la recolección de huiro, aún mantienen un pequeño rancho (aunque abandonado) en la desembocadura de la quebrada de Palo Varao, un par de $\mathrm{km}$ al norte de Agua Dulce, siendo reconocidos hasta hoy -comenta don Humberto- con el apodo de "los Pacheco" o "los buitres", debido a su supuesta afición por alimentarse de todo tipo de animales del monte.

\subsubsection{La caleta de Paposo}

A diferencia de la ciudad de Taltal donde también viven en forma permanente gran parte de las familias paisanas, el carácter costero-rural de la caleta de Paposo, $54 \mathrm{~km}$ al norte de Taltal (Figura 1), otorga un sello característico a este núcleo urbano permanente de 286 habitantes (Castro et al., 2012; Gutiérrez y Lazo, 1996). Como el embarcadero de la antigua Estancia (Hanisch, 1984; Philippi, 1860), la caleta de Paposo se articuló desde el siglo XVII hasta hoy como el principal nucleamiento poblacional para los grupos familiares locales indígena-mestizos, como son los Gutiérrez (el apellido más frecuente), los Morales, los Díaz, los Astudillo, los Castillo, los Almendares y los Mondaca, actuando históricamente Paposo como el nodo que ha articulado las actividades de las majadas y rancheríos, y sobre todo como polo de navegación e intercambio de la producción marina y minera (Capdeville, 2009; Castro et al., 2012; Gutiérrez y Lazo, 1996).

\section{Discusión}

Cotejada la información obtenida de la familia Almendares y de otras fuentes escritas y orales para la comuna de Taltal, entendemos la historia del paisaje rural entre Paposo y Taltal mediante la conformación y articulación de territorios familiares de los grupos camanchaco/chango en el espacio costero. Cada grupo familiar se ha apropiado históricamente de un sector rural muy específico, conformando las denominadas "majadas", las que se constituyen como el espacio doméstico y productivo de un grupo familiar paposino (e.g. Majada de Chugel Díaz, Majada de Cachinalito, Bandurria, Majada de Palo Varao).

Cada majada tiene una historia específica, en torno a ella, más que importar procedimientos legales para su ocupación o adquisición, lo son sobre todo las actividades de subsistencia que la caracterizan y la han caracterizado, sus periodos de abandono y reocupación, y especialmente las alianzas familiares que han permitido y desembocado en la ocupación actual.

Salvo el espacio habitacional específico de cada majada, el resto del territorio de cada una de estas (aguada, playa e interior serrano) no tiene cercos que marquen delimitaciones precisas. El usufructo por parte de extraños en espacios dentro de cada majada está permitido según si exista alianza, castigando su trasposición con la creación de historias que dañarán la honra de la familia infractora (Castelleti, 2017; Gárate, 2011; Gómez Parra, 1998).

Se puede observar una dinámica muy definida en torno a la edificación de las majadas. En general, cada majada está constituida por una casa familiar, la que puede incluso estar en ruinas, dejando claro hasta qué punto la majada ha pasado a definir el paisaje de cada sector costero (e.g. Palo Varao, Agua Dulce). Las casas familiares de las majadas pueden ser de uso permanente o semipermanente, habitando gran parte de la familia permanentemente en los núcleos urbanos de Taltal, Paposo u otros poblados y ciudades. La dinámica ocupacional de cada majada se complementa con la construcción de otros ranchos en el territorio familiar o en playas más alejadas, núcleos habitacionales que son levantados por miembros de la familia una vez que se casan o conviven en pareja, o cuando comiencen a desarrollar algún tipo de actividad económica específica (Castelleti, 2017). 


\section{Conclusiones}

A fuerza, los datos son concluyentes en evidenciar una transformación cultural de los grupos costeros camanchaco/chango de la costa del desierto de Atacama, desde un modo de vida pescadorcazador-recolector a un modo de vida pescador (principalmente centrado en la producción de charquecillo), cabrero o burrero y minero, acaecida desde la implantación de la Estancia de Paposo en 1679 (Castro et al., 2012; Hanisch, 1984).

Resulta notable a la luz del registro oral y escrito obtenido en torno a las familias costeras Almendares y Gutiérrez, observar cómo su modo de vida resulta homologable con aquel atribuido históricamente a "changos", "camanchacos" o "camanchaca", lo que supone una continuidad en la generación de un paisaje que mantiene (y contiene) una tradición pescadora rastreable mediante momentos históricos e incluso precontacto (Aldunate et al., 2010; Castelleti, 2017; Castro et al., 2012, Lozano Machuca 1581), paisaje que además ha semantizado el maritorio o espacio marino (sensu Ther Ríos, 2011), generando así entre los grupos costeros un mapa territorial en constante dinámica y sustentado en un sistema de alianzas familiares, normativas, prácticas y conocimientos pasados por generaciones.

El rastreo de información llevado a cabo resalta la similitud entre el modo de vida que ostentan las familias indígena/mestizas de la costa de Paposo/ Taltal con la tradición camanchaco/chango mencionada en la documentación histórica ${ }^{7}$, lo que sugiere un proceso de mestizaje ya iniciado hacia 1622 como demuestra el LVO (Bittmann, 1977; Casassas, 1974). Corrobora este proceso de continuidad y mestizaje la información obtenida por el equipo de Rothhammer y colaboradores (Henríquez et al., 2004; Rothhammer et al., 2010), quienes han logrado determinar una matriz de distancias genéticas entre las familias actualmente catalogadas como "paisanas" o "changas" en Paposo, describiendo un pasado reciente ligado genéticamente con aimaras, atacameños y más tempranamente con poblaciones chinchorro, generando así estrechas ligazones culturales con otras regiones costeras y de tierra altas, rasgos que se dejan ver con frecuencia en el discurso de los Almendares o de los Gutiérrez (Castelleti, 2017; Gimeno, 2008). Este hecho no hace más que corroborar la histórica constitución pluriétnica y pluricultural del poblamiento de esta zona arreica, en el que un paisaje costero conformado por la convivencia de variados grupos humanos va modelando nuevos sujetos costeros con el aporte local y foráneo.

Notable resulta notar en la balsa de cueros de lobo marino desde previo a la llegada occidental, la tecnología costera característica, la que movilizó -desde temprano- un sistema tradicional de enclaves y asentamientos en torno a los cuales desde momentos históricos se habrían levantado las majadas actuales entre Paposo y Taltal (Figura 1), paisaje tradicional que solo desde hace dos siglos convive con el desarrollo de los centros urbanos de Taltal y Antofagasta (Aldunate et al., 2010; Castro, 2009; Castro et al., 2012; Larraín, 1978). Dicha red ocupacional centrada desde momentos históricos en la producción y distribución de charquecillo además de otros productos costeros, habría generado una alta movilidad de sujetos y segmentos grupales preferentemente masculinos, implicando además el arribo a la costa arreica de objetos, conocimiento y personas desde otros núcleos regionales principalmente altiplánicos, como también de otras zonas costeras (Aldunate et al., 2010; Larraín, 1978). La misma pluriculturalidad descrita para la costa (Aldunate et al., 2010; Castro, 2009; Martínez, 1998) habría generado una convivencia de grupos locales con grupos puquina, aimara o quechua hablantes, como posteriormente también con mapuches y castellanos, resultando el conflictivo proceso de adquisición/imposición de las categorías grupales o etnónimos de "camanchaca", "proanche" y "chango"8 para los grupos costeros (Escobar y García, 2017).

Los datos entregados, creemos, no hacen más que abrir la puerta para futuras investigaciones en la zona de Paposo y Taltal, permitiendo así ser un aporte al proceso de visibilización de la memoria local y en la comprensión acerca de la constitución de las familias camanchaco/chango en el paisaje costero.

\section{Agradecimientos}

Este artículo fue llevado a cabo en el marco del proyecto UTA mayor 3735-18 "Registro y caracterización del área de Chamarcusiña y Ausípar en el valle de Azapa, XV Región de Chile: la aldea de Chilpe". Se agradece a las funcionarias del Archivo Central del Arzobispado de Antofagasta y a los funcionarios del Archivo Central del Arzobispado de La Serena; a Francisca Campano, autora del mapa del estudio; al Departamento 
de Antropología de la Universidad de Tarapacá (UTA); a la Escuela Nacional de Antropología e Historia (ENAH) y a las comunidades de Taltal,
Paposo y las majadas. Finalmente, se agradece también a la revisora Carmen Álvarez Granell y a los evaluadores de este artículo.

\section{Referencias Citadas}

Aldunate, C.; V. Castro y V. Varela

2003 "Oralidad y arqueología: una línea de trabajo en las tierras altas de la región de Antofagasta". Chungara Vol. 35 $\mathrm{N}^{\circ} 2: 305-314$.

Aldunate, C.; V. Castro y V. Varela

2010 "Los atacama y el pescado de Cobija en Homenaje al Maestro John Murra”. En Chungara 42(1): 341-347.

Aravena, P.

2014 Patrimonio, historiografía y memoria social. "presentismo radical” y abdicación de la operación histórica. Diálogo Andino, 45: 77-84.

Ayala. P.

2007 Relaciones entre atacameños, arqueólogos y Estado en Atacama (norte de Chile). Estudios Atacameños, 33: 133-157.

Bermúdez, O.

1987 Breve Historia del Salitre. Sintesis histórica desde sus orígenes hasta mediados del siglo XX. Ediciones Pampa Desnuda. Santiago de Chile.

Bertonio, L.

1956 [1612] Vocabulario de la Lengua Aymara. Juli, Chucuyto: Francisco del Canto (Reeditado en 1879 por Julio Platzmann, Leipzig: Teubner; edición fotostática. La Paz: Don Bosco).

Bittmann, B.

1977 "Cobija y alrededores en la época colonial (1600-1750)". En Actas del VII Congreso de Arqueología de Chile, Vol. II: 327-356. Ediciones Kultrún. Chile.

Bittmann, B.

1984 "Interrelaciones étnicas establecidas a lo largo de la costa del norte de Chile y sur de Perú en el contexto de la Colonia: los Camanchaca”. En Estudios Atacameños No 7: 327-334.

Bollaert, W.

1860 Antiquarian, ethnological and other researches in New Granada, Equador, Peru and Chile with observations of the Pre-Incarial, Incarial, and other monuments of Peruvian nations. Trubner \& Co. London.

Bourdieu, P.

2007 [1980] El Sentido Práctico. Siglo XXI Editores. Argentina.

Capdeville, A.

2009 "Augusto Capdeville Rojas, notas arqueológicas". Introducción, ordenación y textos por Rodolfo Contreras Neira. En Taltalia Revista del Museo Augusto Capdeville Rojas de Taltal: 10-87. Taltal, Chile.

Casassas, J.M.

1974 La Región Atacameña en el siglo XVII. Universidad del Norte, Chile.

Castelleti, J.

2017 Los hijos de la Camanchaca: la "otra" historia-prehistoria de la costa del Desierto de Atacama. Tesis que para optar al grado de Doctor en Estudios Arqueológicos, Escuela Nacional de Antropología e Historia, Ciudad de México. INAH.
Castro, V.

2009 De Ídolos a Santos. Evangelización y Religión andina en los Andes del Sur. Ediciones de la Dirección de Bibliotecas, Archivos y Museos. Centro de Investigaciones Diego Barros Arana-Fondo de Publicaciones Americanistas Universidad de Chile, Santiago de Chile.

Castro, V.; M. Escobar y D. Salazar

2012 "Una mirada antropológica al devenir minero de Taltal y Paposo". En Chungara, Revista de Antropología, Volumen $44 \mathrm{~N}^{\circ}$ 3: 401-417.

Comisión Verdad Histórica y Nuevo Trato con los pueblos indígenas 2008 Informe de la Comisión Verdad y Nuevo Trato con los pueblos indígenas. Editado por el Comisionado presidencial para asuntos indígenas. Gobierno de Chile.

Criado, F.

1999 Del Terreno al Espacio: Planteamientos y Perspectivas para la Arqueología del Paisaje. CAPA 6 Criterios y Convenciones en Arqueología del Paisaje. Universidad de Santiago de Compostela.

David, B. y J. Thomas

2008 "Introduction". Handbook of landscape archaeology. Left coast press.

Dueñas Quispe, A.

2013 Diccionario Quechua de los Incas. Ediciones y Representaciones Multilibros Dueñas. Cusco, Perú.

Escobar, M. y M. García

2017 "Camanchaca. Flujos etnonímicos y neblineros en la costa del norte de Chile". Revista de Geografía Norte Grande, 68: 11-32.

Fernández, E.

2014-2015 El nombre y los apellidos. Su regulación en derecho español y comparado. Tesis doctoral Universidad de Sevilla. Rescatada de https://idus.us.es/xmlui/bitstream/ handle/11441/32106/TESIS\%20definitiva.pdf;sequence=1.

Gárate, $\mathrm{H}$.

2011 Rescate, difusión y puesta en valor del patrimonio cultural popular de la Estancia de Paposo. Core, Región de Antofagasta. Chile.

Gavilán, V. y A.M. Carrasco.

2018 Prácticas discursivas e identidades de género de las mujeres aymaras del norte chileno (1980-2015). Diálogo Andino, 55: 111-120.

Gay, C.

2010 [1854] Atlas de la Historia Física y Política de Chile. Tomos I, II y IV. Dirección de Bibliotecas, Archivos y Museos; Pontificia Universidad Católica de Chile y Cámara Chilena de la Construcción. Chile.

Geertz, C.

1994 [1983] Conocimiento Local. Ensayos sobre la Interpretación de las culturas. Editorial Paidós.

Gimeno, $\mathrm{H}$.

2008 Taltal, a 150 años del sueño de José Antonio Moreno. Ilustre Municipalidad de Taltal. Chile. 
Gómez Parra, D.

1998 La Cultura popular del litoral del desierto. Biblioteca cultura popular II región. Editorial Universidad de Antofagasta. Chile.

González Olguín, D.

1952 [1608] Vocabulario de la lengva general de todo el Perv llamada lengua Qquichua, o del Inca. Universidad Nacional Mayor de San Marcos. Lima.

González Pizarro, J.A.

2002 El Catolicismo en el Desierto de Atacama. Iglesia, Sociedad, Cultura 1557-1987. Ediciones Universitarias. Universidad Católica del Norte. Chile.

Gundermann, $\mathrm{H}$.

2000 "Las organizaciones étnicas y el discurso de la identidad en el norte de Chile, 1980-2000". Estudios Atacameños 19:75-91.

Gutiérrez, G. y L. Lazo.

1996 La estancia ganadera en el área de Paposo. En Plantas medicinales silvestres de uso tradicional en la localidad de Paposo, costa del Desierto de Atacama, II región, Chile. Fondo Nacional de Desarrollo de las Artes y la Cultura, Ministerio de Educación. Chile.

Hanisch, W.S.J.

1984 "Documentos. La Estancia de Paposo y la cuestión de límites". Introducción de Walter Hanisch S.J. En Historia, Vol. 19: 203-218. Pontificia Universidad Católica de Chile.

Henríquez, H.; M. Moraga; E. Llop y F. Rothhammer

2004 "Caracterización genético molecular de habitantes de Caleta Paposo, último reducto Chango en Chile". En Revista Médica de Chile 132: 663-672. Universidad de Chile.

Kalazich, F.

2015 "Memory as Archeology: An Experience of Public Archeology in the Atacama Desert". Public Archeology $14 \mathrm{~N}^{\mathrm{o}} 1: 44-65$.

Kupriienko, S.A.

Sin referencia de año. Idioma Puquina. (2018). www. academia.edu/13121788/Kupriienko_S.A._Idioma_Puquina_ ESPAÑOL-RUSO-ENGLISH_(25 abril 2018).

Larraín, H.

1978 Análisis demográfico de las comunidades de pescadores changos del norte de Chile en el siglo XVI. Thesis presented for the degree of Master of Arts in department of anthropology in State University of New York.

Lazo, L. y E. Téllez

1984 "Los changos del distrito de Paposo a fines de la Colonia: matrícula inédita de habitantes de una población costeña". Revista Futuro Liceos de Taltal, 12-50.

Lizárraga, R. de 1999 [1605 y 1608] Descripción breve de toda la tierra del Perú, Tucumán, Río de la Plata y Chile. Unión Académique Internationale. Academia Nacional de Historia. Buenos Aires.

Lozano Machuca, J.

1992 [1581] "Carta del factor de Potosí Juan Lozano Machuca (al virrey del Perú Don Martín Enríquez) en que da cuenta de cosas de aquella villa y de las minas de los Lipes (año 1581)". Transcripción de J.M. Casassas C. Estudios Atacameños $\mathrm{N}^{\circ} 10,30-34$, Instituto de Investigaciones Arqueológicas y Museo R.P. Gustavo Le Paige S.J. Universidad Católica del Norte, Chile.
Martínez, J.L.

1998 Pueblos del chañar y el algarrobo. Los atacamas en el siglo XVII. Colección de Antropología, DIBAM, Chile.

Matte Varas, J.

1981 "Misión en el Paposo". Teología y Vida, Vol. XXII, 51-64. Facultad de Teología, Pontificia Universidad Católica de Chile. Santiago, Chile.

Mellet, J.

1824 Viajes por el interior de la América Meridional. Imprenta I encuadernación Universitaria. Santiago de Chile.

Philippi, R.A.

1860 Viage al Desierto de Atacama. Gobierno de Chile. Librería de Eduardo Antón.

Ricoeur, $\mathrm{P}$.

2003 [1969] El Conflicto de las interpretaciones. Ensayos de Hermenéutica. Fondo de Cultura Económica.

Rock Núñez, M.E.

2016 Memoria y oralidad: formas de entender el pasado desde el presente. Diálogo Andino, 49: 101-122.

Romero, A.

2003 "Arqueología y pueblos indígenas en el extremo norte de Chile". Chungara Vol. 35, No 2.

Rothhammer, F.; M. Moraga; C. Santoro y B. Arriaza

2010 "Origen de los Changos. Análisis de ADNmt antiguo sugiere descendencia de pescadores de la cultura Chinchorro (7.900-4.000 A.P.)". En Revista Médica de Chile 138: 251-256.

Sagredo, R. y J.I. González

2004 La Expedición Malaspina en la frontera austral del Imperio Español. Santiago, Chile: Centro de Investigaciones Diego Barros Arana y Editorial Universitaria.

Salazar, D.; V. Figueroa; P. Andrade; H. Salinas; L. Olguín; X.

Power; S. Rebolledo; S. Parra; H. Orellana y J. Urrea

2015 Cronología y organización económica de las poblaciones arcaicas de la costa de Taltal. En Estudios Atacameños $\mathrm{N}^{\circ}$ 50: 7-46.

Sayago, C.M.

1997[1874] Historia de Copiapó. Editorial Francisco de Aguirre, Buenos Aires-Santiago de Chile.

Thayer Ojeda, L.

1989 [1906-1919] Orígenes de Chile: elementos étnicos, apellidos, familias. Editorial Andrés Bello, Chile.

Ther Ríos, F.

2011 "Configuraciones del tiempo en el mar interior de Chiloé y su relación con la apropiación de los territorios marítimos". En Desenvolvimento e Meio Ambiente $\mathrm{N}^{\circ} 23$ : 67-80. Editora UFPR.

Villagrán, C.; M. Romo y V. Castro

2003 "Etnobotánica del sur de los andes de la primera región de Chile: un enlace entre las culturas altiplánicas y las de quebradas altas del Loa superior". Chungara 35(1):73-124.

Villagrán, C. y V. Castro

2012 Ciencia indígena de los Andes del norte de Chile. Editorial Universitaria. Chile.

\section{Documentos:}

Libro I de Bautismos Parroquia San Francisco Javier de Taltal, ACDEAA. 1879-1893.

Libro VII de Bautismos Parroquia San Francisco Javier de Taltal, ACDEAA. 1907.

Autos de 1758, ACALS. 


\section{Notas}

1 Si bien se registran sínodos católicos que desde el siglo XIII buscaron ordenar el registro bautismal, matrimonial y de defunciones en parroquias en suelo español, como los de Salamanca de 1369, Burgos 1443, Jaén de 1492, entre otros, no es sino hasta los sínodos diocesanos de Alcalá de Henares (1497) y Talavera de la Reina (1498) llevados a cabo por el cardenal Cisneros, arzobispo de Toledo, que la regularización en la inscripción con nombre y apellido hereditario de los bautizados en las parroquias es institucionalizada por la Corona y el Clero, primero en suelo peninsular y luego del Concilio de Trento (1545-1563) en todos los territorios de ultramar (Fernández, 2014-2015).

2 Es común en Paposo/Taltal el registro de apellidos que varían en su inscripción o transcripción, como sucede con Almendares escrito como Almendarez, Almendariz e inclusive Almendar, correspondiendo probablemente a núcleos familiares que derivan de un tronco común. Para la variación del apellido Zuleta a Suleta se corroboran errores de transcripción, no descartando variaciones en la inscripción bautismal.

3 Traducción: "En Punta Grande había tres o cuatro familias de changos, y en Agua Dulce media docena más, quienes tenían unas pocas cabras y asnos. Habiendo atravesado el peligroso Paso Malo, llegué al Hueso Parado, 25³0' (este lugar se me mostró como el punto divisorio con Bolivia). En Salinas encontré cuatro o cinco familias de changos; y como ellos habían sido entonces recién abastecidos con vino por los compradores de su pescado seco, los bailes grotescos y los cantos continuaron toda la noche".

4 El registro de las entrevistas y diálogos con Humberto Almendares, por respeto a su persona, no fueron grabados sino que se tomaron notas de campo postentrevista.

5 Probablemente del quechua kharuchay, kharunchay o kharunchakuy, "alejar" "alejarse" (Dueñas Quispe 2013) o Anchuni ("alejarse” según González Olguín, 1952; también en Dueñas Quispe, 2013).

6 Pueblo originario trashumante proveniente del Altiplano meridional andino o del noroeste argentino, que hacia el siglo XIX migró hacia las cuencas formativas de los ríos Copiapó y Salado (Comisión Verdad Histórica y Nuevo Trato, 2008).

$7 \quad$ Al respecto, Philippi (1860) es concluyente, pues "La Hacienda de Paposo que pertenece actualmente a la familia Gallo (...) Es sabido que en la conquista de Chile el terreno fue repartido por los conquistadores junto con los indios que vivían en él, y que por el curso de los siglos son ahora los inquilinos" (p. 28).

8 La etimología puquina (Kupriienko s/f), define el vocablo kamanchaqa como "día nublado" (caman=día, chaqa=río, nublado), pudiendo también denotar "los que claman por la sangre o los que sangran" (de cam o kami "sangre, consanguinidad" y la partícula -ch o -ncha, tercera persona plural, junto al verbo cha o chu "clamar, venerar"), resultando una traducción que además de aludir a su hábito de untarse sangre en el cuerpo (Lizárraga 1999), también denotaría la presencia de una representación identitaria de consanguinidad costera en torno a la sangre o el color rojo (Castro 2009, Kupriienko s/f). Posteriormente aimaras y luego también quechuas del interior con los que los grupos costeros se interrelacionaron, para referirse a los diversos grupos costeros les denominaron los ccamachatha (secar cosas y otras cosas según Bertonio en 1612, en probable alusión a su práctica de secar pescado) o camanchaka ("ronquera" según González Olguín en 1608, donde caman=experticia y chaka=garganta, literalmente "los que producen la ronquera") en alusión a la llegada de la neblina a los oasis interiores en los que habitaban los grupos altiplánicos (Bertonio, 1956; Escobar y García, 2017; González Olguín, 1952).

De esta manera, las características que para el forastero presentaban los grupos costeros podría haber incidido en su catalogación bajo tal o cual etnónimo (Escobar y García, 2017). Como ejemplo, el verbo quechua carunchay ("alejarse", según Dueñas Quispe 2013) o anchuni ("alejarse" según González Olguín, 1952 y Dueñas Quispe, 2013), parece ser la raíz del apellido actual chango Caruncho, probablemente un intento por agrupar a las familias de áreas costeras marginales por parte de los grupos altiplánicos en pos del comercio del pescado seco, observando Casassas (1974) que hacia 1646-1662 estos grupos marginales podrían corresponder a camanchacas "no convertidos" al cristianismo.

La denominación Chango para los grupos costeros correspondería a una homogeneización étnica a que fueron sometidos primero por la Corona española desde el siglo XVII y fuertemente desde el XVIII, y luego por los estados nacionales desde el siglo XIX, los habitantes costeros del desierto de Atacama para insertarles en su sistema de producción minera y marina (Bittmann, 1984; Castelleti, 2017; Castro, 2009; Escobar y García, 2017). 